Article

\title{
Monitoring Geologic Hazards and Vegetation Recovery in the Wenchuan Earthquake Region Using Aerial Photography
}

\author{
Zhenwang Li ${ }^{1,2}$, Quanjun Jiao ${ }^{1}$, Liangyun Liu ${ }^{1, *}$, Huan Tang ${ }^{1,2}$ and Tong Liu ${ }^{1}$
}

1 Institute of Remote Sensing and Digital Earth, Chinese Academy of Sciences, Beijing 100094, China; E-Mails: lizhenwang10@ hotmail.com (Z.L.); jiaoqj@radi.ac.cn (Q.J.); tanghuan_2011@hotmail.com (H.T.); tliu@ceode.ac.cn (T.L.)

2 Institute of Agricultural Resources and Regional Planning, Chinese Academy of Agricultural Sciences, Beijing 100094, China

* Author to whom correspondence should be addressed; E-Mail: liuly@ radi.ac.cn; Tel.: +86-10-8217-8163; Fax: +86-10-8217-8177.

Received: 25 November 2013; in revised form: 4 March 2014 / Accepted: 10 March 2014 / Published: 19 March 2014

Abstract: On 12 May 2008, the 8.0-magnitude Wenchuan earthquake occurred in Sichuan Province, China, triggering thousands of landslides, debris flows, and barrier lakes, leading to a substantial loss of life and damage to the local environment and infrastructure. This study aimed to monitor the status of geologic hazards and vegetation recovery in a post-earthquake disaster area using high-resolution aerial photography from 2008 to 2011, acquired from the Center for Earth Observation and Digital Earth (CEODE), Chinese Academy of Sciences. The distribution and range of hazards were identified in 15 large, representative geologic hazard areas triggered by the Wenchuan earthquake. After conducting an overlay analysis, the variations of these hazards between successive years were analyzed to reflect the geologic hazard development and vegetation recovery. The results showed that in the first year after the Wenchuan earthquake, debris flows occurred frequently with high intensity. Resultantly, with the source material becoming less available and the slope structure stabilizing, the intensity and frequency of debris flows gradually decreased with time. The development rate of debris flows between 2008 and 2011 was $3 \%$ per year. The lithology played a dominant role in the formation of debris flows, and the topography and hazard size in the earthquake affected area also had an influence on the debris flow development process. Meanwhile, the overall geologic hazard area decreased at $12 \%$ per year, and the vegetation recovery on the landslide mass was 
$15 \%$ to $20 \%$ per year between 2008 and 2011. The outcomes of this study provide supporting data for ecological recovery as well as debris flow control and prevention projects in hazard-prone areas.

Keywords: Wenchuan earthquake; landslide; debris flow; vegetation recovery; aerial photography

\section{Introduction}

On 12 May 2008, the 8.0-magnitude Wenchuan earthquake occurred in Sichuan Province, China. Its epicenter was located at Yingxiu Town, Wenchuan County, in the east of the Longmenshan Fault Zone on the eastern fringe of the Tibetan Plateau. The Wenchuan earthquake caused substantial casualties and financial losses. In response to the massive energy this earthquake released, thousands of geologic failures were triggered such as landslides and debris flows, in addition to the formation of barrier lakes [1,2]. These failures caused enormous damage to the local environment and ecosystem [3], and destabilized numerous hillsides and solid masses, increasing the probability of geologic disasters [4]. Particularly in the mountainous areas, the damage caused by earthquake-triggered secondary geologic failures may have been more severe than the immediate damage caused by the earthquake itself [5].

After the earthquake, timely estimating the development of geo-hazards and disaster conditions through field investigation was necessary for hazards assessment and decision making. However, damaged roads, unstable hillsides, inclement weather, and frequent aftershocks made it difficult to perform field work and acquire reliable information about the areas. Remote sensing is an effective means for the timely monitoring and quantitative assessment of devastated areas [6]. Remote sensing data can be acquired at broad spatial and temporal scales, and provide useful information for rapid damage assessment at an early stage when field surveys of a large area are difficult [7]. Remote sensing data have been available for approximately one century and have proven useful in natural-hazard investigation and management in response to a number of natural disasters [8-14]. Today, as remote sensing technology develops toward being multiplatform, multispectral, high-resolution, and multi temporal, it has become more convenient to use in hazard assessment and rapid monitoring [15].

Much research has been conducted on the Wenchuan earthquake using optical remote sensing data [16-18] and multi-mode radar data [11,19,20], focusing on disaster monitoring [21-25], hazard assessment [26-29], mitigation [30,31] and vegetation damage assessment [3,32]. Chigira et al. [33] discussed the distribution and characteristics of seismically triggered landslides from the Wenchuan earthquake using satellite images. Huang and $\mathrm{Li}$ [34] studied the distribution of geo-hazards triggered by the earthquake, and identified a total of 11,308 geo-hazards in sixteen seriously damaged counties based on field investigations, air photos, and satellite imaging data. Ge et al. [35] estimated the damage to vegetation caused by the secondary hazards of the Wenchuan earthquake through SPOT and aerial images. The authors found that farmland and grassland were less damaged than forestland because of the steep slopes and that the damage to the vegetation first decreased and then increased with increasing distance from the three main faults of the Longmenshan fault zone. Liu et al. [36] evaluated the vegetation degradation caused by the earthquake and its recovery two months after the 
disaster from the analysis of MODIS Gross Primary Productivity (GPP) time series products and other ancillary GIS data. $\mathrm{Xu}$ and $\mathrm{Lu}$ [37] summarized a meta-synthesis pattern of the post-disaster recovery and reconstruction by comparing studies of 14 earthquakes in the last 100 years. The authors found that remarkable achievements have been made with respect to post-Wenchuan earthquake recovery and reconstruction and that these post-disaster recovery and reconstruction programs can be used as a foundation for future earthquake recovery.

Moreover, dynamic monitoring of geologic hazards triggered by the earthquake and aftershocks in successive years using remote sensing data is necessary and important to uncover the mechanism and influence factors in the geological processes. Because of the limited availability of images at a very high spatial resolution (suitable for detecting geologic hazards) acquired periodically over the same area, long-term careful monitoring of post-earthquake disaster development and vegetation recovery through images are rarely conducted. In our research, satellite imagery from before the earthquake and four epochs of high-resolution airborne optical images after the Wenchuan earthquake were utilized to monitor and assess the development of secondary geologic hazards (refers to the geologic hazards triggered by the Wenchuan earthquake or aftershocks in this paper) by focusing on 15 representative large-scale geologic hazard sites in the affected areas. The condition of the vegetation recovery was also analyzed in the context of the landslides and debris flows, and variation rate was displayed to illustrate their development at different stages after the Wenchuan earthquake. Besides, geological and topographic factors were also analyzed to discover the hazard development and recovery trajectories. The results provide scientific data of the vegetation recovery and hazard development, which can be used for prevention and reconstruction practices in the Wenchuan earthquake area.

\section{Study Area}

The Wenchuan earthquake occurred along the Longmenshan fault, a thrust structure along the border of the Indo-Australian Plate and Eurasian Plate. Seismic activities were concentrated along its mid-fracture (known as the Yingxiu-Beichuan fracture), causing substantial loss of life and damage to property, infrastructure, and the environment. Our study areas were the focus of the overlapping flight zones covered by airborne optical images acquired between 2008 and 2011 (see Figure 1). This area covered most of the counties that were severely damaged by the Wenchuan earthquake, totaling approximately 20,000 $\mathrm{km}^{2}$. These counties and cities include Beichuan County, Wenchuan County, Mianzhu City, Shifang City, Dujiangyan City, Pengzhou City, Mianyang City, Jiangyou City, and Pingwu County. The region is characterized by mountainous topography where the elevation ranges from $500 \mathrm{~m}$ to over $6000 \mathrm{~m}$. The complex geologic structure of the study area makes it highly susceptible to landslides and debris flows.

\section{Data and Methods}

\subsection{Data Acquisition}

Immediately after the Wenchuan earthquake, an emergency project, Monitoring and Assessment of the Wenchuan Earthquake Disasters by Remote Sensing, was initiated by the Chinese Academy of 
Sciences (CAS). A large number of remote sensing images of various types were acquired between 15 and 28 May 2008, for disaster assessment and rapid monitoring and evaluation of the severely damaged areas. The spatial resolution of these images ranged from 0.5 to $0.8 \mathrm{~m}$ depending on the flight altitude. During the subsequent years, airborne optical remote sensing images covering most of the heavily affected areas were again acquired in 2009, 2010, and 2011 to monitor the process of environmental restoration and reconstruction [38]. In our study, we used airborne optical images from 2008 to 2011 acquired from the Center for Earth Observation and Digital Earth (CEODE), CAS, to analyze the hazards development and ecological recovery in the earthquake-affected areas. Table 1 shows the flight task details.

Figure 1. Airborne imagery across the earthquake region (background: Landsat TM image in 2007).

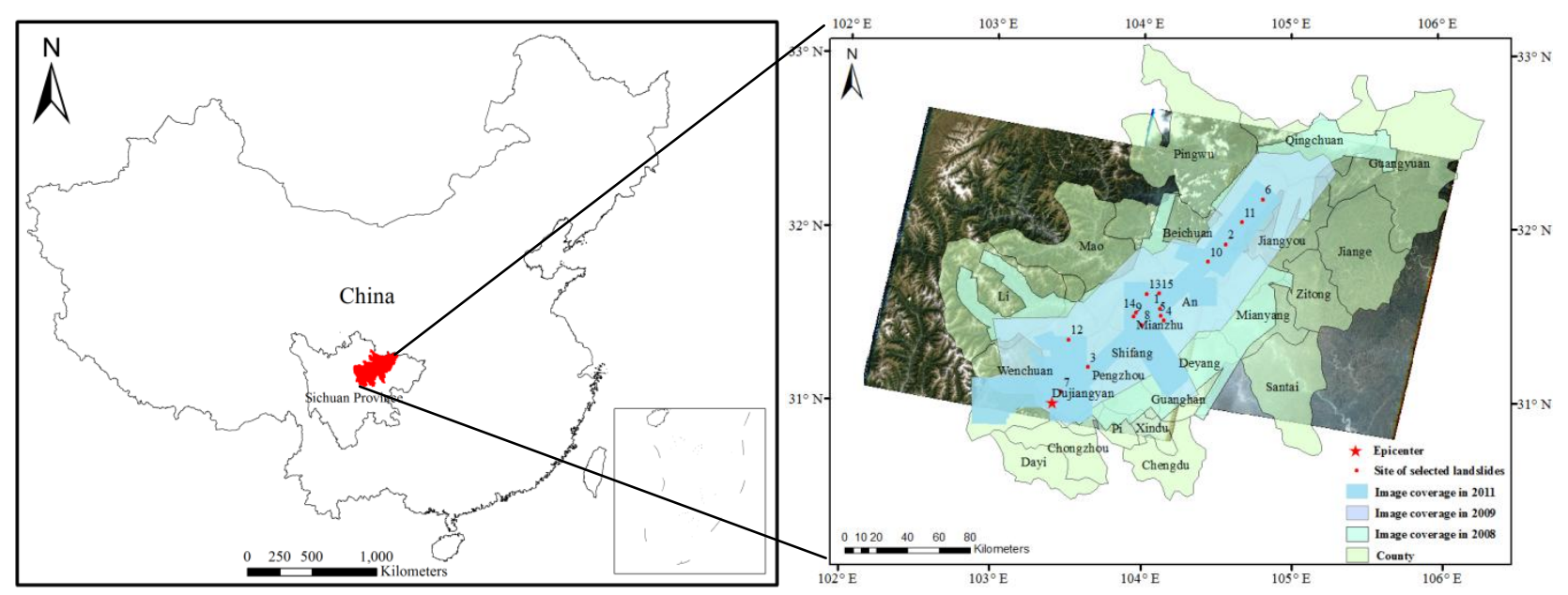

Table 1. Remote sensing data acquired over the earthquake-damaged area.

\begin{tabular}{cccccc}
\hline Flight Year & Flight Data & Sensor & Image Resolution & Number of Images & Flight Area $\left(\mathbf{k m}^{\mathbf{2}}\right)$ \\
\hline 2008 & 15 May-28 May & ADS40 & $0.5-0.7 \mathrm{~m} / 2 \mathrm{~m}$ & 99 & 36,744 \\
2009 & 16 May-03 June & ADS80 & $0.5 \mathrm{~m} / 5 \mathrm{~m}$ & 108 & 33,266 \\
2010 & 18 April-04 May & UCXp & $0.3 \mathrm{~m} / 4 \mathrm{~m}$ & 78 & Approximately 10,000 \\
2011 & 17 May-07 June & UCXp & $0.3 \mathrm{~m} / 4 \mathrm{~m}$ & 57 & 20,125 \\
\hline
\end{tabular}

Note: the number before "/" in the "image resolution" column refers to the original spatial resolution, the number after " $"$ refers to the spatial resolution after resizing.

The spectral bands of the acquired images include blue, green, and red. The airborne sensors had a high spatial resolution, ranging from 0.3 to $0.7 \mathrm{~m}$. However, the large data size and non-uniform image resolution made the images difficult to manage, thus after acquiring the images, CEODE resized the images to a uniform resolution. In addition, a systematic orthorectification of all the airborne images was conducted using the 25-m DEM data interpolated from 1:50,000 scale topographic maps [38], except for the year of 2010 because of the lack of Position and Orientation System (POS) data.

Auxiliary data used in this study included a Sichuan administrative vector map; 30-m resolution Digital Elevation Model (DEM) data (scene ID: srtm_57_06 and srtm_58_06) obtained by the Shuttle Radar Topography Mission (SRTM) and acquired for this study from the Land Cover Facility, University of Maryland; the China geological map, produced by the China Geological Survey, to acquire the lithology 
data; and 30-m resolution Landsat TM images from 2007 (entity ID: LE71290382007262PFS00 and LE71300382007141SGS00) acquired from the United States Geological Survey to reflect the land cover before the earthquake.

\subsection{Method}

\subsubsection{Region Selection}

A landslide is a downslope movement of rock or soil occurring on the surface of a rupture in which much of the material often moves as a coherent or semi-coherent mass with little internal deformation $[39,40]$. Landslides triggered by the earthquake often showed the following characteristics on remote sensing images: vegetation was disturbed, the deposits could be clearly identified at the foot of the slope along roads or rivers, and the interrupted region showed a bright white or dark brown contrast compared with the surrounding slopes. Debris flow is a common type of fast-moving mass movement in which loose soil, rock, and sometimes organic matter combine with water to form a slurry that flows downslope [41]. Debris flows usually start on steep hillsides as liquefied shallow landslides, and continue flowing down and through channels, accumulating water, sand, mud, trees, and other material. When the flows reach canyon mouths or flatter ground, the debris spreads over a broad area [42]. On remote sensing images, debris flows are usually characterized as an obvious flow channel and forms a large alluvial fan at the foot of the slope (Figure 2b).

Figure 2. Airborne remote sensing images of Wenjiagou, Qingping Town, Mianzhu City (site No. 1) taken on 23 May 2008 (a) and 7 July 2011 (b).

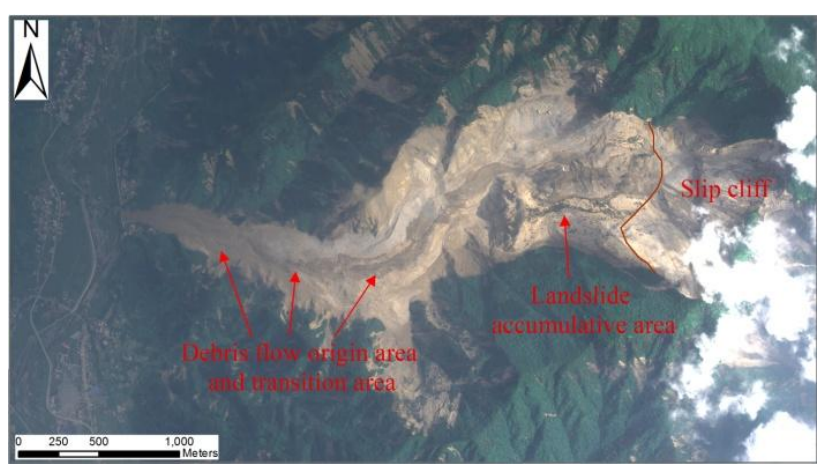

(a)

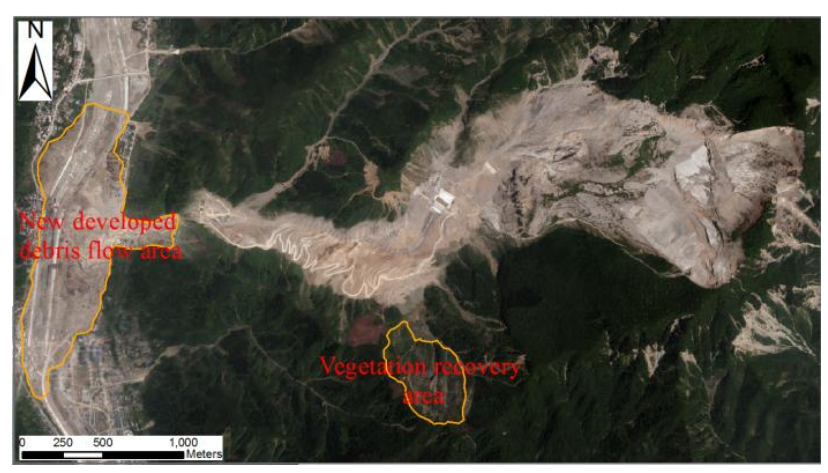

(b)

After the earthquake, aftershocks and heavy rain led to thousands of secondary geologic hazards, including landslides, debris flows, and barrier lakes. To illustrate the changes representing environmental restoration and human settlement reconstruction, representative study areas were selected. In this study, we first used a visual interpretation method to select large-scale landslides by comparing a Landsat TM image from 2007 and airborne optical images from 2008 and finally selected 15 geologic hazard sites distributed throughout the severely damaged areas (red points in Figure 1) with high quality of minimal or no cloud contamination in most of the flight year above the site. Each hazard site contained several landslides, with the locations and attributes shown in Table 2. Then, the corresponding images covering every hazard site were selected from 2008, 2009, and 2011 airborne optical images. Because of the poor data quality of the images from 2009 of the No. 14 site and from 2008 of the No. 15 site, 
the analyses of these two sites' secondary geologic hazard development were based on images from 2008, 2010, and 2011 and from 2009, 2010, and 2011, respectively.

Table 2. Statistics for the 15 geologic hazard sites.

\begin{tabular}{|c|c|c|c|c|c|c|}
\hline \multirow{2}{*}{ No. } & \multirow{2}{*}{ Location } & \multicolumn{3}{|c|}{ Image Date } & \multirow{2}{*}{$\begin{array}{l}\text { Number of } \\
\text { Landslides }\end{array}$} & \multirow{2}{*}{$\begin{array}{c}\text { Total Area in } \\
2008 \text { (ha) }\end{array}$} \\
\hline & & 2008 & 2009 & 2011 & & \\
\hline 1 & Wenjiagou, Qingping Town, Mianzhu City & 23 May & 03 June & 07 June & 1 & 260.33 \\
\hline 2 & Chenjiaba, Beichuan County & 28 May & 18 May & 31 May & 23 & 631.63 \\
\hline 3 & East Yingxiu Town, Wenchuan County & 23 May & 16 May & 07 June & 8 & 121.68 \\
\hline 4 & Hanwang Town, Mianzhu City & 19 May & 16 May & 25 May & 11 & 113.30 \\
\hline 5 & Tianchi Town, Mianzhu City & 23 May & 16 May & 25 May & 12 & 148.18 \\
\hline 6 & Shawan, Nanba Town, Pingwu County & 28 May & 18 May & 31 May & 3 & 48.49 \\
\hline 7 & Yingxiu Town, Wenchuan County & 23 May & 03 June & 28 May & 14 & 664.73 \\
\hline 8 & Jinhelinkuang, Mianzhu City & 23 May & 03 June & 07 June & 12 & 616.85 \\
\hline 9 & Jiuding Mountain, Bailongchi, Mianzhu City & 23 May & 16 May & 25 May & 2 & 110.33 \\
\hline 10 & Tangjiashan, Beichuan County & 27 May & 18 May & 31 May & 27 & 487.14 \\
\hline 11 & Guanzhipu, Beichuan County & 28 May & 18 May & 31 May & 13 & 155.32 \\
\hline 12 & Jinchi Town, Wenchuan County & 24 May & 21 May & 28 May & 5 & 191.11 \\
\hline 13 & Gaochuan County, Jinyang City & 23 May & 16 May & 25 May & 6 & 373.82 \\
\hline $14 *$ & Changheba, Mianzhu City & 23 May & miss & 25 May & 2 & 141.90 \\
\hline $15 *$ & Daguangbao Group, An County & miss & 16 May & 25 May & 4 & 959.59 \\
\hline
\end{tabular}

Note: "*” used here in the No. 14 and 15 sites indicates that the missing data are infilled with data from 28 April 2010 and 27 April 2010, respectively.

\subsubsection{Geometric Registration}

Although the acquired aerial images were subjected to geometric and orthorectification corrections, there was still position deviation to a certain extent because of the complex terrain. After comprehensive consideration of the image quality and position error compared with the Landsat TM image, we selected airborne images from 2009 as our reference images, and selected 100 to 150 control points at each hazard site to complete the geometric registration of the images from 2008, 2010, and 2011. In addition, the China geological map was projected in UTM coordinates (WGS84 datum), the same as Landsat image.

\subsubsection{Detection of Geologic Hazards}

The mountainous parts of the study area had high vegetation cover prior to the earthquake, spatially covering up to $80 \%$ of the entire region [43]. Earthquake-induced geologic hazards such as landslides and debris flows lead to large-scale vegetation interruption and some feature changes in the landscape, including the color, texture, and shape. These distinctive features help with identification of failure areas in remote sensing images. Figure 2 presents the airborne remote sensing images of landslides and debris flows in Qingping Town in 2008 and 2011.

After geometric registration and post-processing, the airborne optical images were used to construct maps in true color and were analyzed for hazard damage monitoring. Using an interactive interpretation method between pre-earthquake Landsat TM images and post-earthquake optical 
airborne images, the 15 selected geologic hazard areas from 2008, 2009, and 2011 were carefully interpreted in the ArcGIS platform through polygons drawn based on the specific features and differences described in Section 3.2.1.

Based on the interpretation results, the slope failure and vegetation recovery areas were obtained by performing an overlay analysis with the previous year's failure areas. After eliminating newly developed landslide mass areas and areas with registration errors on the overlay analysis results through artificial screening, every site's newly developed debris flow areas (the newly emerged hazard area caused by debris flows) were obtained. Then, the vegetation recovery areas based on the previous failure areas were calculated with Equation (1). The rates of vegetation recovery, debris flow development, and geologic hazard variation were calculated with Equation (2).

$$
\begin{aligned}
& n a=o a+p-e r \\
& \text { rate }=\frac{\mathrm{var}}{o a^{*} \text { years }}
\end{aligned}
$$

In Equation (1), na refers to the bare failure area after the vegetation recovered; $o a$ is the bare failure area prior to vegetation recovery; $p$ is the newly developed debris flow area; and er is the vegetation recovery area based on the previous failure region. In Equation (2), rate refers to the variation rate of the three objects, years refers to the years apart of analyzed variables, and var refers to the three analysis objects. In this paper, var equals $(o a-n a)$ if the object is geologic hazard variation, $p$ if the object is debris flow development, and er if the object is vegetation recovery.

\subsection{Field Investigation}

To verify the interpretation results and identify the reason for various hazard developments, in-situ surveys were conducted from 6 to 13 May 2012 in several large slope movements. The field investigation covered most of the selected hazard sites (except for No. 8, No. 9 and No. 14) that were relatively easy to access, no equipment was used during the survey, and basic conditions in each site were recorded manually. The elements recorded included the soil structure (mainly particle composition), human activity (whether good for hazard prevention and recovery), and vegetation recovery conditions (yes or no) and patterns (naturally or artificially). Because of the complex conditions in each site for the large area and combined hazard group, the survey results were not listed here and were used in the following section to explain the remote sensing based results. Several example in-situ photos are shown in Figure 3.

\section{Results}

\subsection{Multi-Temporal Detecting Geological Hazards}

The 2008, 2009, and 2011 secondary geologic hazard areas, as determined by the above analysis, are shown in Table 3. This table shows that during the first year after the earthquake, the secondary geologic hazard development differed greatly among sites, with five sites experiencing an increased area and ten sites experiencing a decreased area. In 2011, however, almost all of the sites, except No. 14 and No. 15, experienced a decrease in hazard area, although at varying rates. The changes of 
geological hazards between 2008 and 2011 of several hazards are shown in Figure 4. From the monitoring results, the variations of geological hazards could be classified into four cases. The first case was for a continuous decrease in hazard area from 2008 to 2011 that included No. 2, No. 4, No. 5 , No. 6, No. 7, No. 8, No. 12 and No. 13, accounting for 53.3\% of all sites. The second case was for an increase in hazard area from 2008 to 2009, and a decreased hazard area in the next two years, such as the No. 3, No. 10, No. 11 and No. 15 sites. The third case was for a decreased area from 2008 to 2009 and an increase in hazard area in the next two years, such as the No. 1 and No. 9 sites. The last case was for a continuous increase in hazard area from 2008 to 2011, which pertained only to site No. 14 . Nonetheless, from 2008 to 2011, the overall geologic hazard area decreased as vegetation growth rate exceed that of debris flow development, and the geologic hazards variation rate between 2008 and 2011 was approximately 12\%, which was higher than the rate of the first year after the earthquake.

Figure 3. Photos taken at geologic hazard sites during the field investigation in May 2012. (a) Vegetation recovery in Yingxiu Town, Wenchuan County (site No. 7); (b) Old Beichuan Town, Beichuan County (site No. 10); (c) The huge failure in Tangjiashan, Beichuan County (site No. 10); (d) Vegetation recovery on the failure slope in Qingping Town, Mianzhu City (site No. 1).

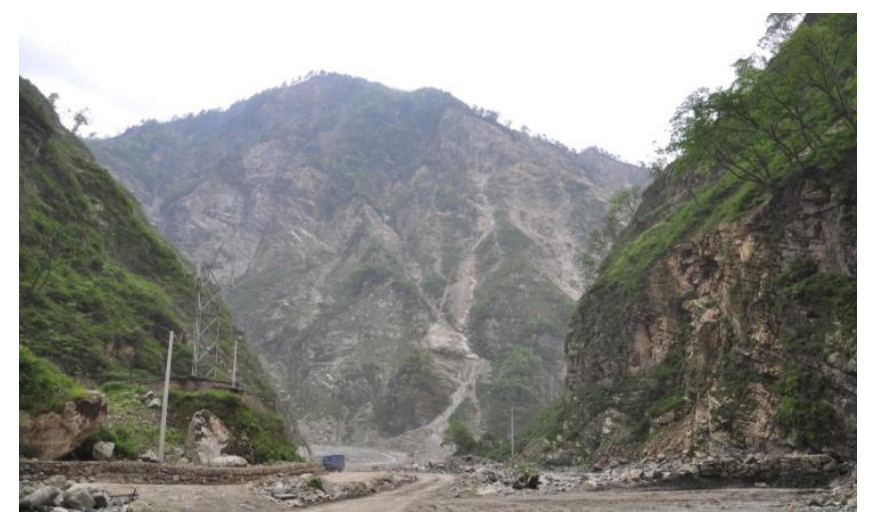

(a)

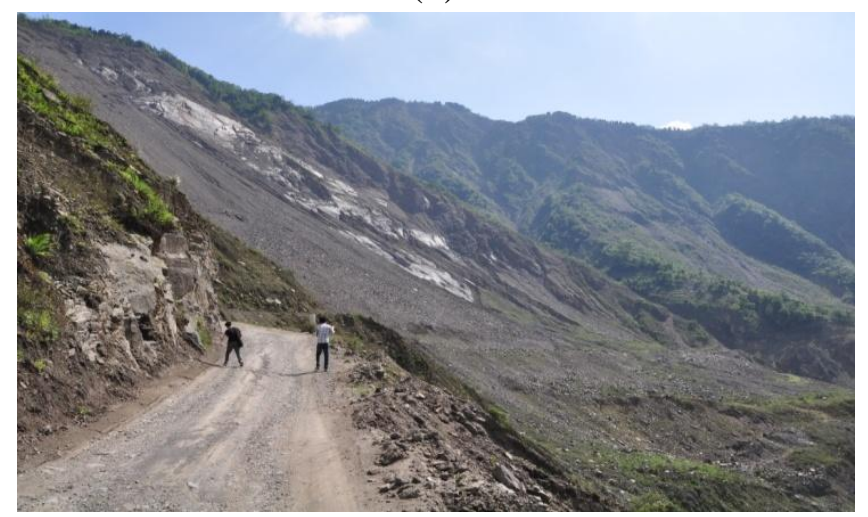

(c)

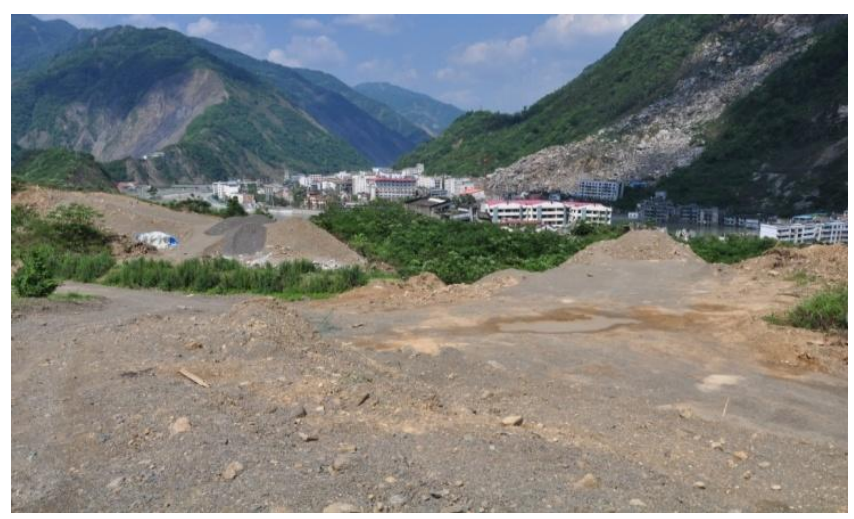

(b)

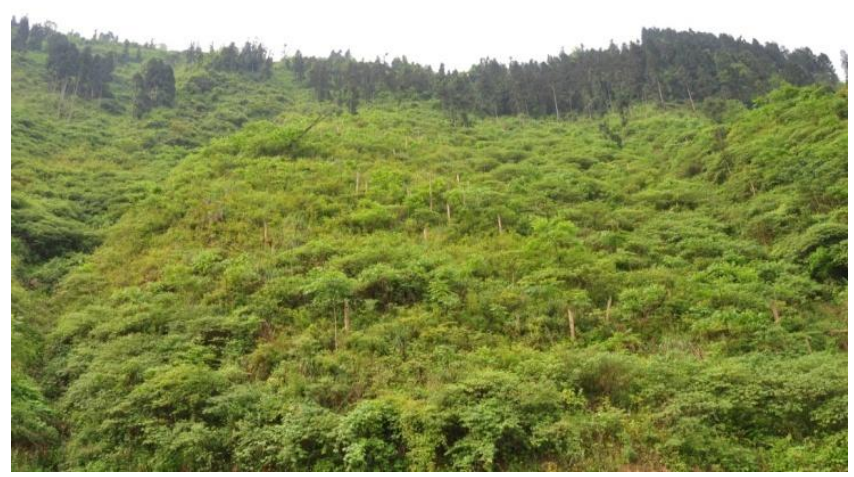

(d) 
Table 3. Each site's geologic hazard area and variation rate.

\begin{tabular}{|c|c|c|c|c|c|c|c|c|c|}
\hline \multirow{2}{*}{ No. } & \multicolumn{3}{|c|}{ Geologic Hazard Area (ha) } & \multicolumn{3}{|c|}{ Geologic Hazard Variation Area (ha) } & \multicolumn{3}{|c|}{ Geologic Hazard Variation Rate (per year) } \\
\hline & 2008 & 2009 & 2011 & 2008-2009 & 2009-2011 & 2008-2011 & 2008-2009 & 2009-2011 & 2008-2011 \\
\hline 1 & 260.33 & 232.70 & 235.03 & -27.63 & 2.34 & -25.29 & 0.11 & -0.01 & 0.03 \\
\hline 2 & 631.63 & 626.37 & 323.61 & -5.26 & -302.76 & -308.02 & 0.01 & 0.24 & 0.16 \\
\hline 3 & 121.68 & 122.09 & 107.11 & 0.41 & -14.98 & -14.57 & -0.003 & 0.06 & 0.04 \\
\hline 4 & 113.30 & 86.60 & 53.21 & -26.70 & -33.39 & -60.09 & 0.24 & 0.19 & 0.18 \\
\hline 5 & 148.18 & 129.20 & 88.81 & -18.98 & -40.39 & -59.37 & 0.13 & 0.16 & 0.13 \\
\hline 6 & 48.49 & 45.58 & 39.74 & -2.91 & -5.84 & -8.75 & 0.06 & 0.06 & 0.06 \\
\hline 7 & 664.73 & 454.83 & 265.57 & -209.89 & -189.26 & -399.16 & 0.32 & 0.21 & 0.20 \\
\hline 8 & 616.85 & 602.69 & 463.49 & -14.16 & -139.20 & -153.36 & 0.02 & 0.12 & 0.08 \\
\hline 9 & 110.33 & 102.74 & 105.83 & -7.59 & 3.09 & -4.51 & 0.07 & -0.02 & 0.01 \\
\hline 10 & 487.14 & 516.83 & 351.75 & 29.70 & -165.08 & -135.39 & -0.06 & 0.16 & 0.09 \\
\hline 11 & 155.32 & 163.12 & 109.39 & 7.80 & -53.73 & -45.93 & -0.05 & 0.16 & 0.10 \\
\hline 12 & 191.11 & 154.99 & 111.55 & -36.12 & -43.44 & -79.56 & 0.19 & 0.14 & 0.14 \\
\hline 13 & 373.82 & 230.04 & 224.42 & -143.77 & -5.63 & -149.40 & 0.38 & 0.01 & 0.13 \\
\hline 14 & 141.90 & $153.84(2010)$ & 164.60 & 11.94 & 10.76 & 22.70 & -0.04 & -0.07 & -0.05 \\
\hline 15 & 959.59 (2009) & $972.15(2010)$ & 951.05 & 12.56 & -8.53 & 12.56 & -0.01 & 0.01 & -0.01 \\
\hline Total & 3922.91 & 3467.78 & 2479.51 & -455.10 & -988.27 & -1443.40 & 0.116 & 0.142 & 0.123 \\
\hline
\end{tabular}

Note: In the column of "geologic hazards variation rate", positive numbers represent an decrease in hazard area; negative numbers represent a increase in hazard area; with regard to the No. 14 and No. 15 sites, the columns "2008-2009," "2008-2011," and "2009-2011" correspond to "2008-2010," "2009-2010," and "2010-2011," respectively, the "Total" row is the accumulation of the first thirteen hazards sites, and does not include the last two.

Figure 4. Airborne remote sensing images of several hazards in 2008, 2009, and 2011, respectively (from left to right). (a) The big landslide and debris flow of Wenjiagou, Qingping Town, Mianzhu City (site No. 1); (b) The big landslide group happened at Yingxiu Town, Wenchuan County (site No. 7); (c) The change of hazard happened at Tangjiashan, Beichuan County (site No. 10); (d) The change of hazard happened at Changheba, Mianzhu City (site No. 14); (e) The change of Daguangbao hazard group, An County (site No. 15).
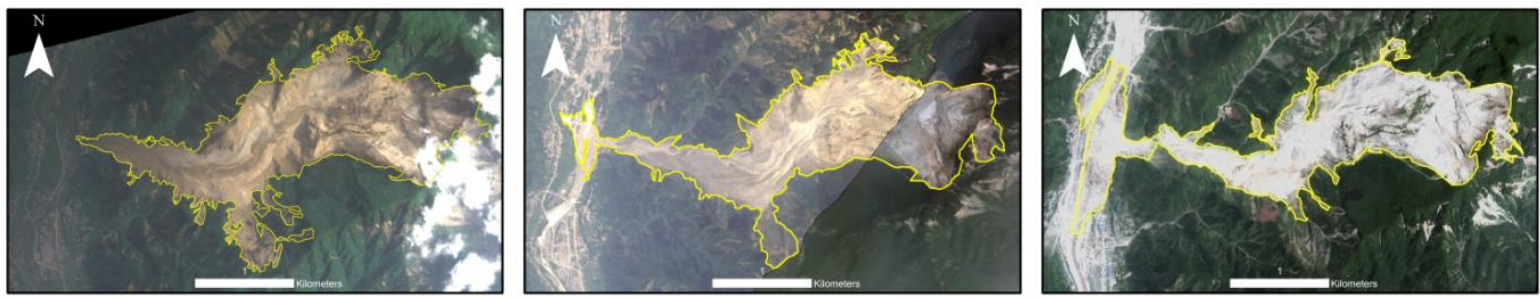

(a)
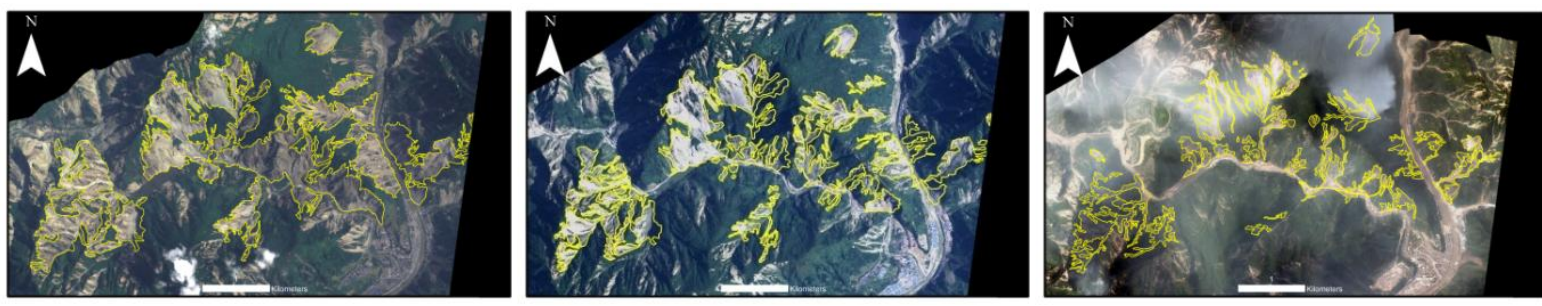

(b) 
Figure 4. Cont.
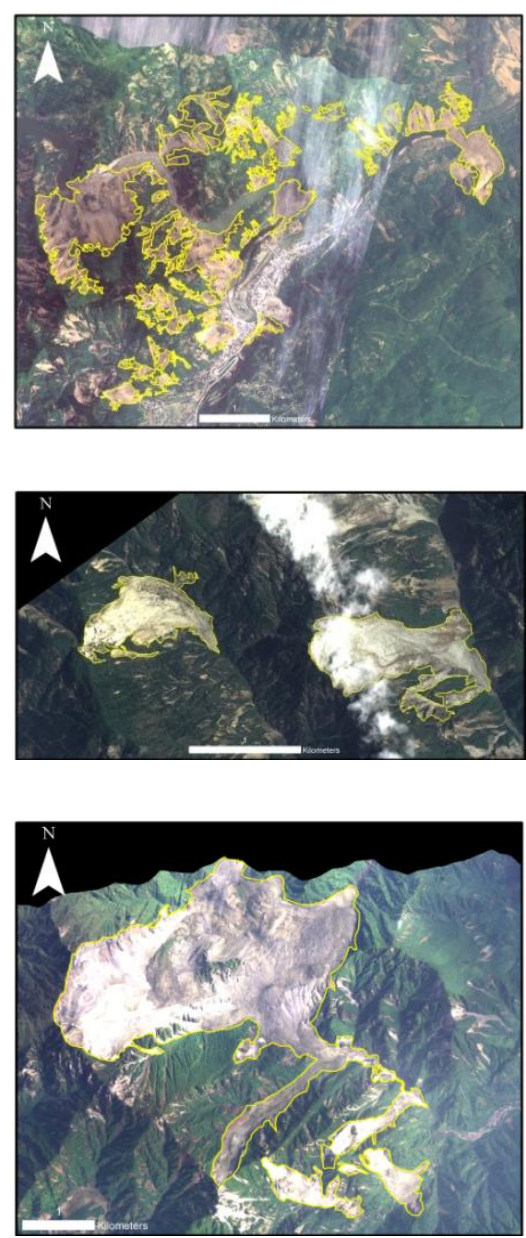

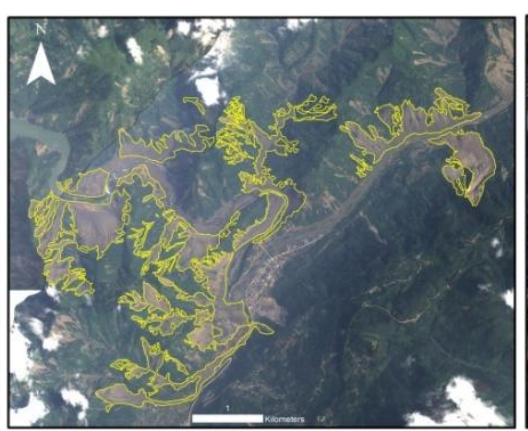

(c)

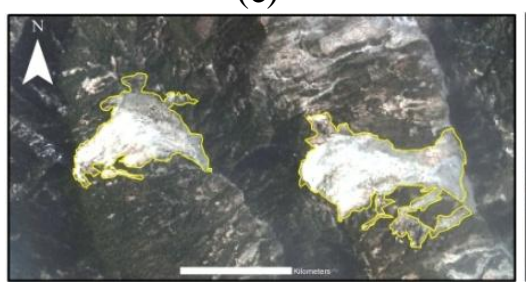

(d)

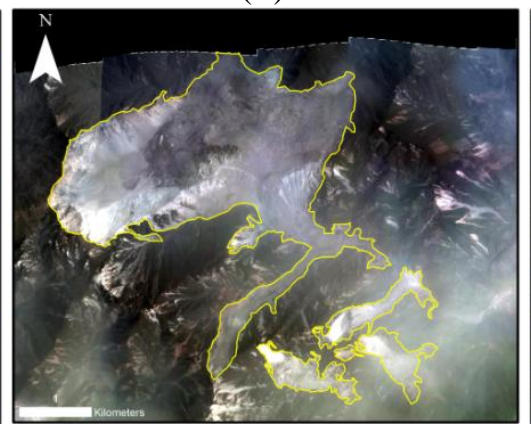

(e)
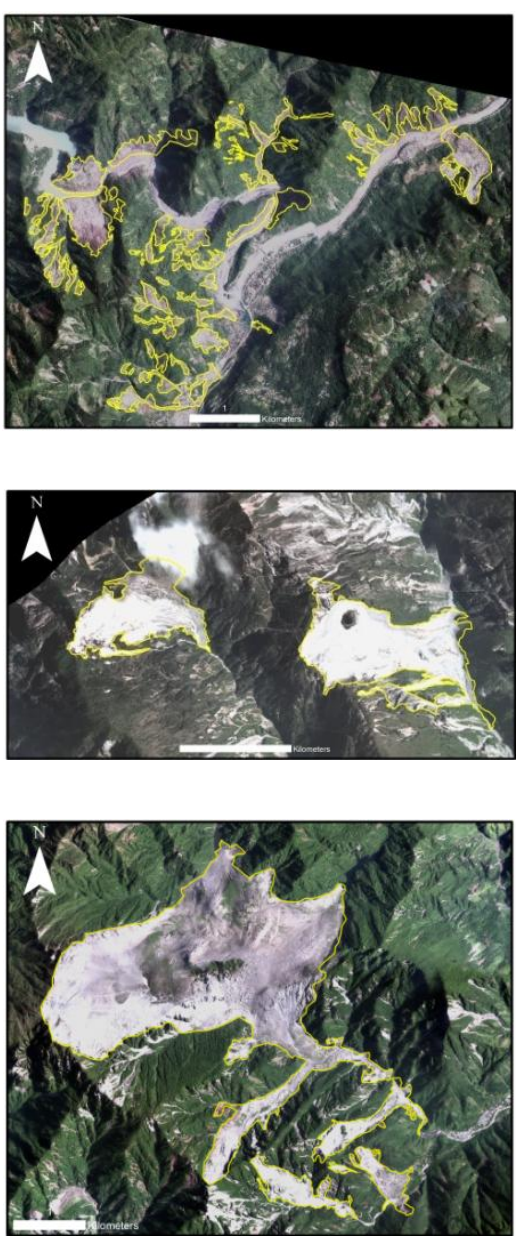

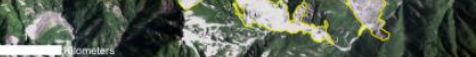

Figure 5. Changes in the debris flow regions of site 1, 10, 14, 15 from 2008 to 2009 and from 2009 to 2011.
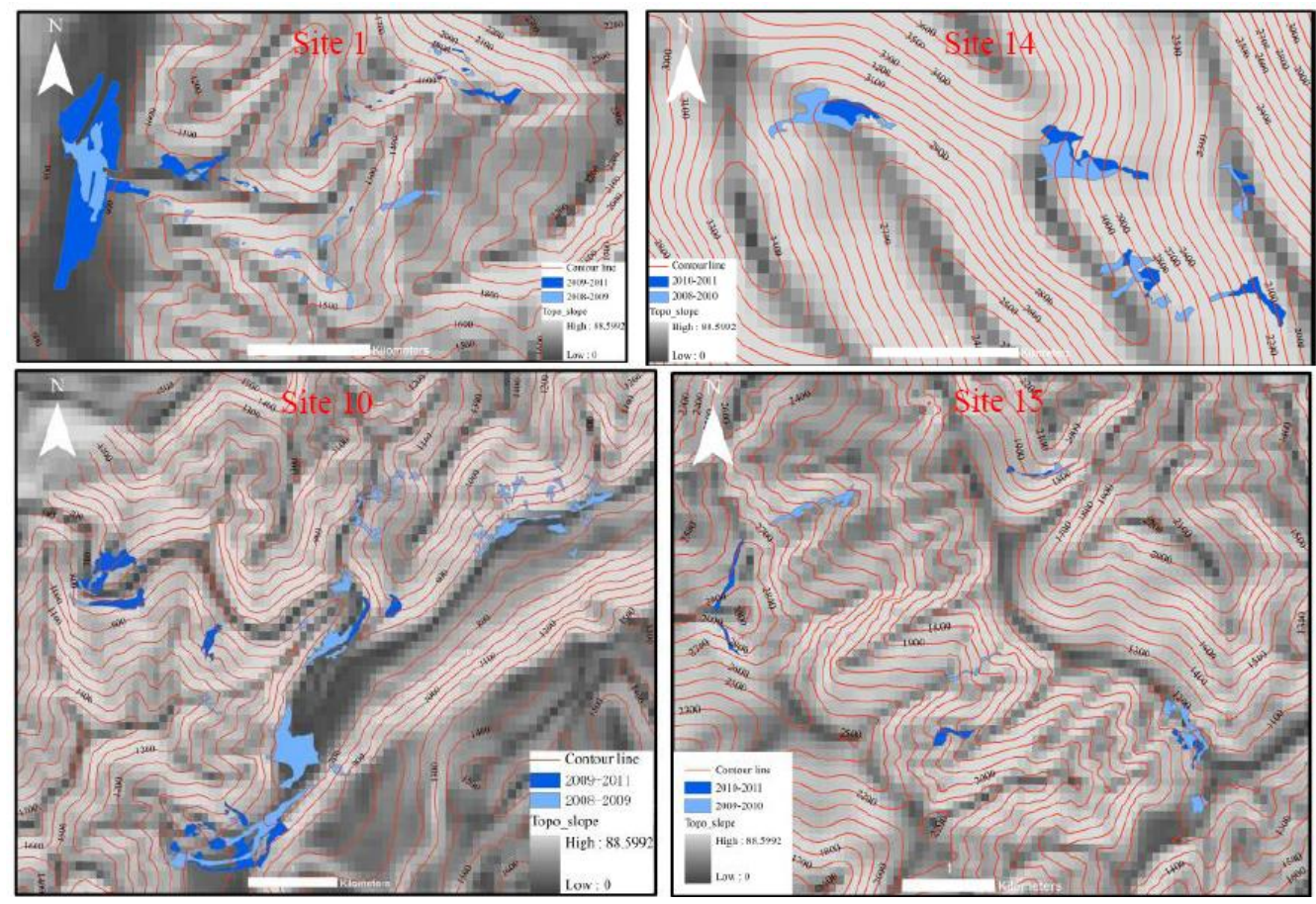


\subsection{Multi-Temporal Detecting Debris Flows}

After acquiring the geologic hazard areas from 2008, 2009, and 2011, the newly developed debris flow regions were obtained utilizing an overlay analysis between successive years. Table 4 presents the development of debris flows from 2008 to 2009 and from 2009 to 2011, and debris flow variation region of several typical sites were illustrated in Figure 5. During the first year after the earthquake, the activity of debris flows was particularly severe, causing the development of many new hazards areas. After two years, the activity gradually decreased but was still occurring. The developed areas and rates are shown in Table 4. From 2008 to 2009, the newly developed debris flow areas reached 402.05 ha, which was far larger than the average area that developed in the next two years, and the development rate was almost triple that between 2009 and 2011. In general, the average development rate in these three years for the entire region was 3\%, which is in accordance with Chen's study [44].

Table 4. Each site's newly developed debris flow areas and rates.

\begin{tabular}{|c|c|c|c|c|c|c|}
\hline \multirow{2}{*}{ No. } & \multicolumn{3}{|c|}{ Newly Developed Debris Flow Area (ha) } & \multicolumn{3}{|c|}{ Debris Flow Development Rate (per year) } \\
\hline & 2008-2009 & 2009-2011 & 2008-2011 & 2008-2009 & 2009-2011 & 2008-2011 \\
\hline 1 & 23.46 & 49.22 & 58.45 & 0.09 & 0.11 & 0.07 \\
\hline 2 & 147.89 & 78.78 & 104.52 & 0.23 & 0.06 & 0.06 \\
\hline 3 & 15.64 & 29.19 & 30.42 & 0.13 & 0.12 & 0.08 \\
\hline 4 & 15.69 & 0.00 & 7.00 & 0.14 & 0.00 & 0.02 \\
\hline 5 & 24.01 & 7.98 & 14.29 & 0.16 & 0.03 & 0.03 \\
\hline 6 & 9.07 & 2.98 & 4.75 & 0.19 & 0.03 & 0.03 \\
\hline 7 & 0.00 & 0.00 & 0.00 & 0.00 & 0.00 & 0.00 \\
\hline 8 & 35.39 & 0.00 & 17.63 & 0.06 & 0.00 & 0.01 \\
\hline 9 & 3.11 & 7.79 & 7.21 & 0.03 & 0.04 & 0.02 \\
\hline 10 & 84.75 & 45.93 & 63.13 & 0.17 & 0.04 & 0.04 \\
\hline 11 & 31.73 & 0.00 & 19.58 & 0.20 & 0.00 & 0.04 \\
\hline 12 & 0.00 & 7.26 & 0.00 & 0.00 & 0.02 & 0.00 \\
\hline 13 & 11.31 & 6.94 & 15.14 & 0.03 & 0.02 & 0.01 \\
\hline 14 & $20.24(2008-2010)$ & $13.88(2010-2011)$ & $25.37(2008-2011)$ & 0.07 (2008-2010) & 0.09 (2010-2011) & $0.06(2008-2011)$ \\
\hline 15 & $19.72(2009-2010)$ & $12.43(2010-2011)$ & $29.88(2009-2011)$ & $0.02(2009-2010)$ & $0.01(2010-2011)$ & $0.02(2009-2011)$ \\
\hline Total & 402.05 & 236.07 & 342.12 & 0.102 & 0.034 & 0.029 \\
\hline
\end{tabular}

Note: The "Total" row is the accumulation of the first thirteen hazards sites and does not include the last two. The years in the bracket of site No. 14 and No. 15 refers to the start and end years of variation.

\subsection{Multi-Temporal Detection of Vegetation Recovery on Previously Bare Landslide Masses}

In this study, vegetation recovery refers to the vegetation growth based on the previous year's hazard region. Figure 4 in Section 4.1 also illustrates the vegetation recovery in the 15 selected sites (the decreasing area from 2008 to 2011). For most sites, the recovery conditions were very positive, and vegetation began to grow on the previously bare landslide mass. Utilizing Equation (1), the vegetation recovery areas were calculated. The results are shown in Table 5. In addition, the vegetation recovery region of several sites was illustrated in Figure 6 using overlay analysis in ArcGIS platform. The fastest vegetation recovery period occurred in the first year after the earthquake, which is in line 
with the development of debris flows, with a recovery rate of $21.9 \%$. Subsequently, the vegetation recovery rate trended down. In terms of the overall condition from 2008 to 2011, the average rate was $15 \%$ to $20 \%$. The vegetation on the landslide mass may require at least five to ten years to completely recover.

\subsection{Relationships between Vegetation Recovery and Debris Flow Development}

The vegetation recovery rate, the debris flow development rate and the geologic hazard variation rate are shown in Figure 7. The variations of the three rates from 2008 to 2011 were in close agreement, and the vegetation recovery rate was higher than that of each site's geologic hazards variation rate. In geologic hazard areas, debris flow activity interrupts vegetation regrowth, so the faster debris flows develop, the slower the vegetation recovers, and the slower the geologic hazard varies. Figure 6 shows that, in most hazard sites, the vegetation recovery rate was higher than the debris flow development rate from 2008 to 2011, and the geologic hazard area values of the sites (except for No. 14 and 15) decreased.

Figure 6. Vegetation recovery of site 1, 7, 10, 14, 15 from 2008 to 2009 and from 2009 to 2011 .
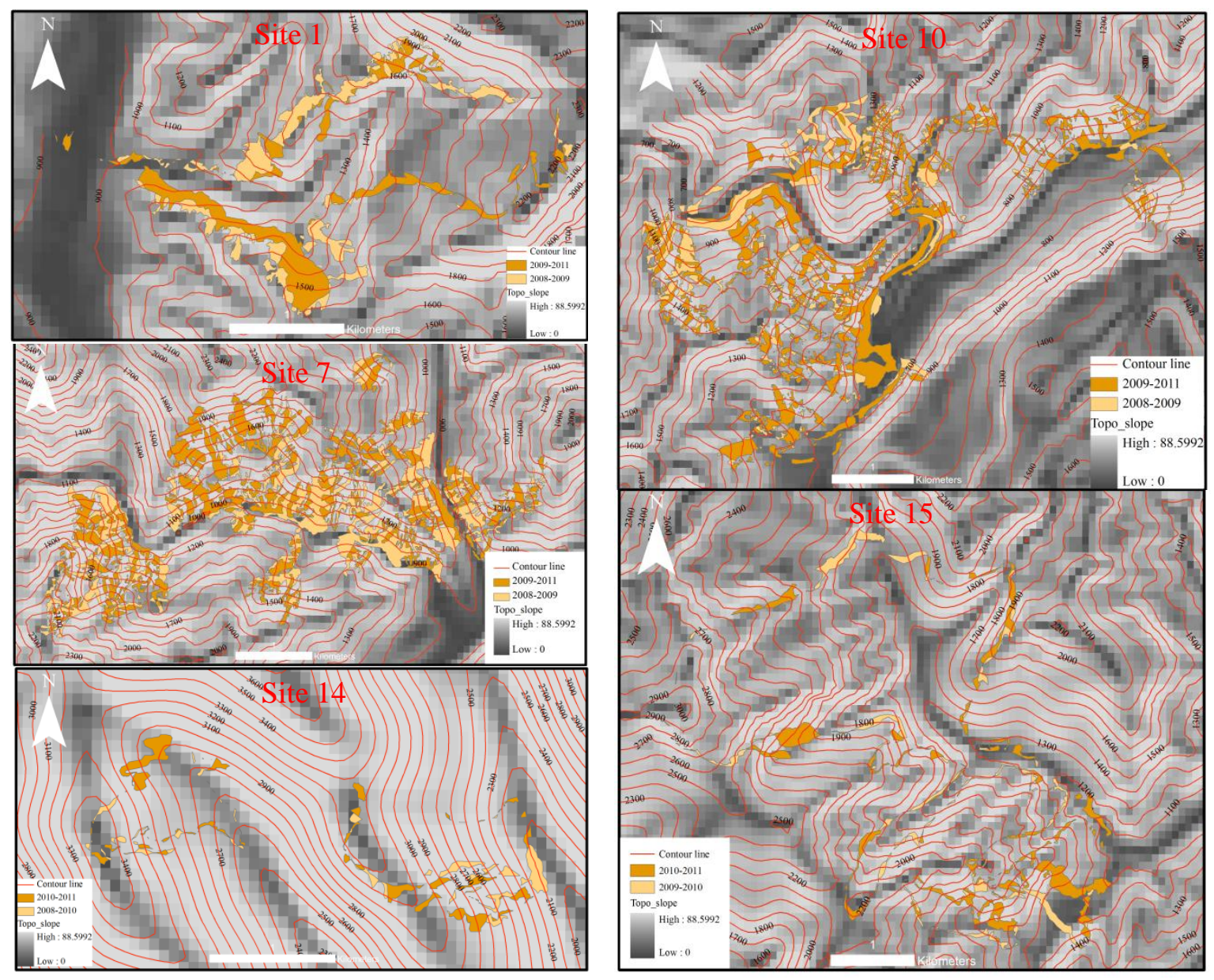
Table 5. Area and rate of vegetation recovery on previously bare landslide masses.

\begin{tabular}{|c|c|c|c|c|c|c|}
\hline \multirow{2}{*}{ No. } & \multicolumn{3}{|c|}{ Area of Vegetation Recovery (ha) } & \multicolumn{3}{|c|}{ Rate of Vegetation Recovery (per year) } \\
\hline & 2008-2009 & 2009-2011 & 2008-2011 & 2008-2009 & 2009-2011 & 2008-2011 \\
\hline 1 & 51.09 & 46.89 & 83.74 & 0.20 & 0.10 & 0.11 \\
\hline 2 & 153.14 & 381.54 & 412.53 & 0.24 & 0.30 & 0.22 \\
\hline 3 & 15.23 & 44.17 & 44.99 & 0.13 & 0.18 & 0.12 \\
\hline 4 & 42.39 & 33.39 & 67.09 & 0.37 & 0.19 & 0.20 \\
\hline 5 & 43.00 & 48.37 & 73.67 & 0.29 & 0.19 & 0.17 \\
\hline 6 & 11.98 & 8.81 & 13.50 & 0.25 & 0.10 & 0.09 \\
\hline 7 & 209.89 & 189.26 & 399.16 & 0.32 & 0.21 & 0.20 \\
\hline 8 & 49.55 & 139.20 & 170.99 & 0.08 & 0.12 & 0.09 \\
\hline 9 & 10.71 & 4.70 & 11.71 & 0.10 & 0.02 & 0.04 \\
\hline 10 & 55.05 & 211.02 & 198.52 & 0.11 & 0.20 & 0.14 \\
\hline 11 & 23.94 & 53.73 & 65.51 & 0.15 & 0.16 & 0.14 \\
\hline 12 & 36.12 & 50.71 & 79.56 & 0.19 & 0.16 & 0.14 \\
\hline 13 & 155.09 & 12.57 & 164.54 & 0.41 & 0.03 & 0.15 \\
\hline 14 & $8.30(2008-2010)$ & $3.13(2010-2011)$ & 2.67 (2008-2011) & $0.03(2008-2010)$ & $0.02(2010-2011)$ & $0.01(2008-2011)$ \\
\hline 15 & $7.16(2009-2010)$ & $33.53(2010-2011)$ & 38.41 (2009-2011) & $0.01(2009-2010)$ & $0.03(2010-2011)$ & $0.02(2009-2011)$ \\
\hline Total & 857.18 & 1224.36 & 1785.51 & 0.22 & 0.18 & 0.15 \\
\hline
\end{tabular}

Note: The "Total" row is the accumulation of the first thirteen hazards sites and does not include the last two. The years in the bracket of site No. 14 and No. 15 refers to the start and end years of variation.

Figure 7. Comparison of hazard development rates from 2008 to 2011.

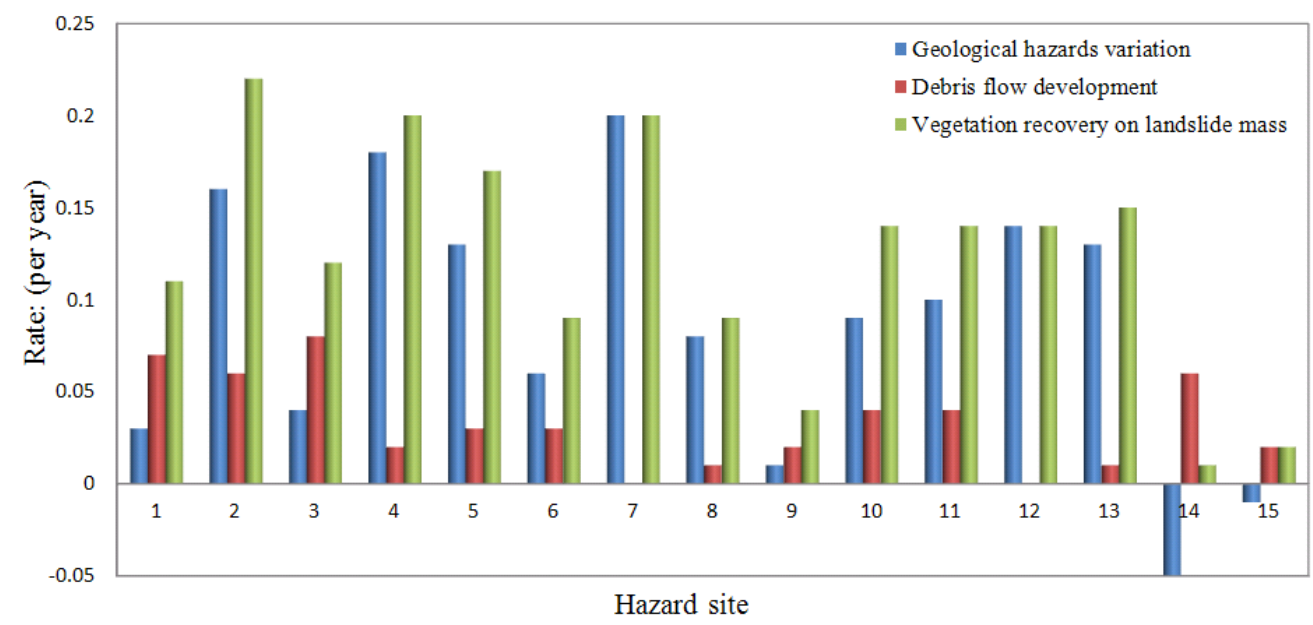

\section{Discussion}

\subsection{Geologic Hazards Development in the Earthquake Triggered Hazard Areas}

A study by Qi et al. [45] showed that earthquakes (including aftershocks) and heavy rainfall were powerful causes of landslide hazards, and earthquake-induced landslides and rainfall-induced landslides could couple to form a disaster chain. A record from the Sichuan Earthquake Networks Center showed that, after the Wenchuan earthquake and up until June 2011, 88,000 aftershocks surrounding the Longmenshan fault were detected, among which more than 400 aftershocks were larger than 
4.0 magnitude [46], and the occurrence of aftershocks was especially intense in the northeastern segment of the fault, which had some connection with the increased stress in this region [47]. Meanwhile, heavy rainfall occurred on 23 and 24 September 2008, reaching 250-350 mm and triggering new landslides and active old landslides, causing debris flow hazards to occur in groups [45]. Considering the four geologic hazard cases examined in Section 4.1 of this paper, the first case is relatively stable-aftershocks and heavy rainfall had little influence on the landslide mass, so the vegetation growth rate was faster than the hazard increase rate. For the second case, the geologic hazard variation is in accordance with the distribution of aftershocks and heavy rainfall. A study from Hua et al. [48] also showed that the aftershocks along the Longmenshan fault happened mainly within one year after the earthquake (Figure 8), and geodynamics and spatial pattern of vegetation damage was affected by rupture zones [49]. For the third and fourth cases, the geologic hazards are unstable, and the debris flow development of these two cases is consistent with human activity. For example, the anomalous variation of No. 9 and No. 14 sites was related to the Changheba Dam construction.

Figure 8. Map of aftershocks (up until 31 December 2008) and surface rupture zones of the Wenchuan earthquake region.

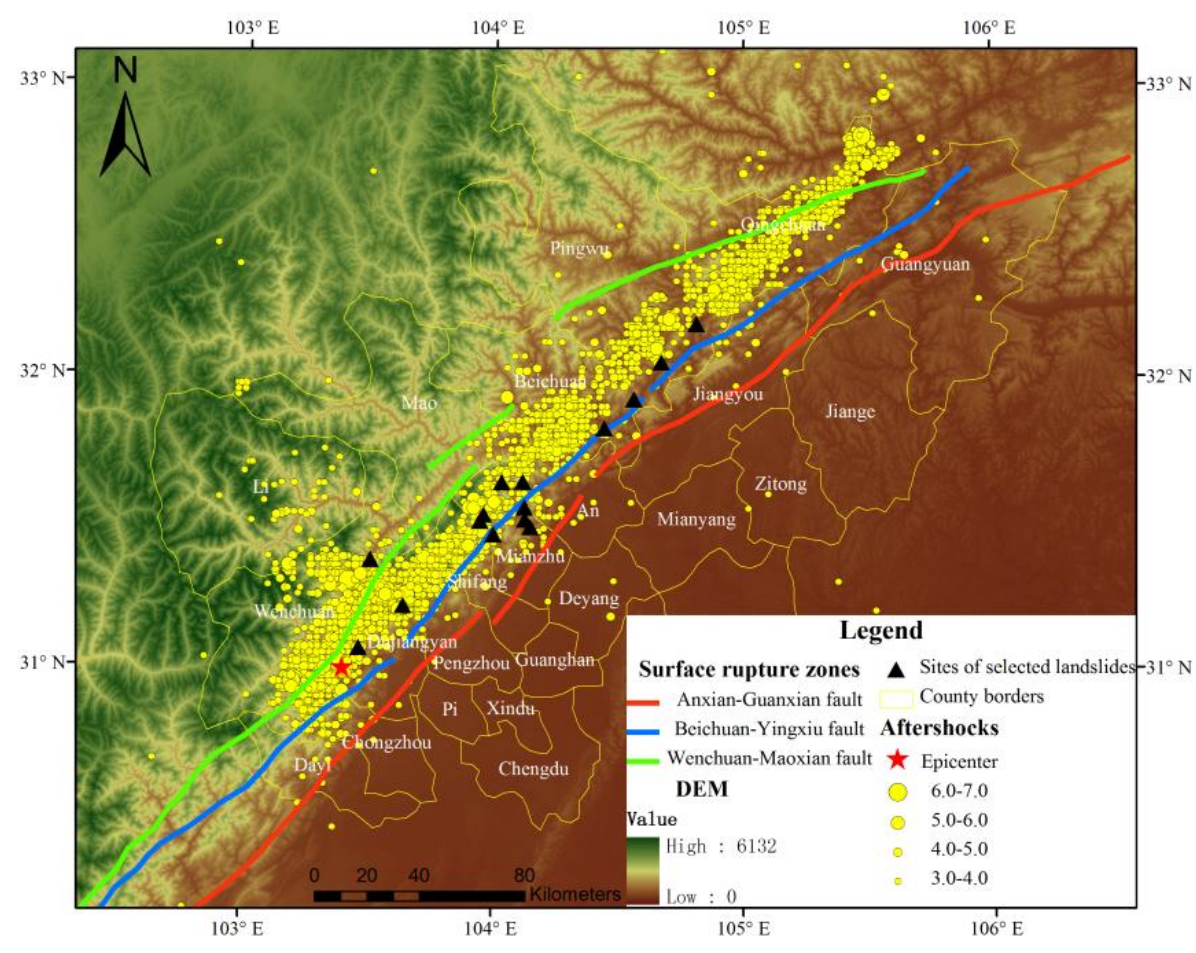

Considering the whole hazard area, the recovery of hazards was comparatively slow in the first year after the earthquake, when the area suffered the most intense aftershocks and heavy rainfalls. The rate was $11.6 \%$, less than the average speed of recovery. After 2009, slopes became more stable and the vegetation on the landslides recovered rapidly, with an annual recovery rate of $12 \%$. Through field investigation, we found that some artificial measures and natural vegetation recovery (Figure 9d) were important for the development of debris flows, such as the hazard prevention projects, ecological restoration projects (Figure 9a,b) and cultivated land reclamation (Figure 9c) in the earthquake affected areas slowed down the progress of debris flow in some extend. 
Figure 9. (a) Hazard prevention project in Yingxiu Town, Wenchuan County (site No. 7); (b) Human activity in Wenjiagou, Qingping Town (site No. 1); (c) Reclamation on the landslide mass in Chenjiaba, Mianzhu City (site No. 4); (d) Natural vegetation recovery in Chenjiaba, Mianzhu City (site No. 4).
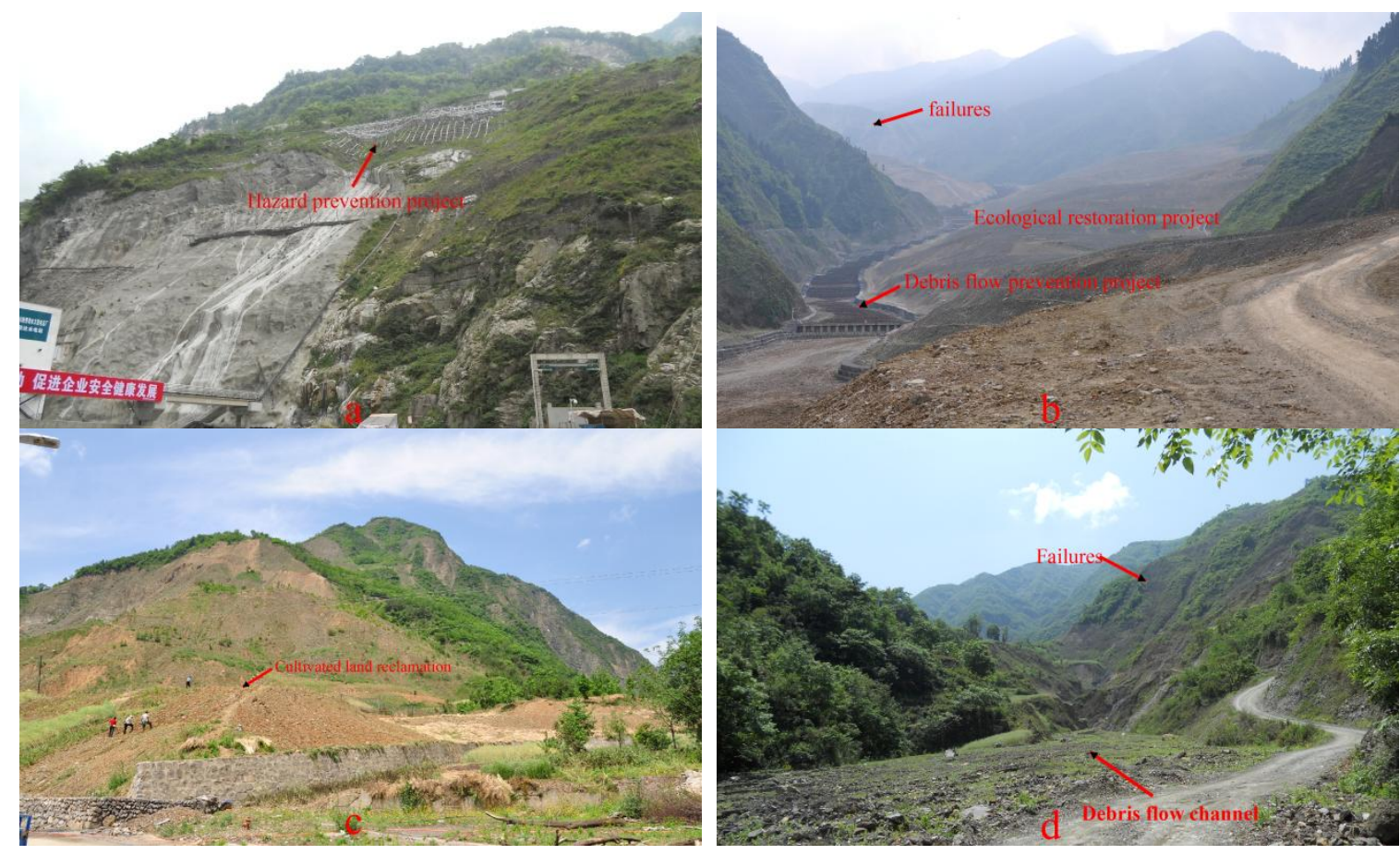

\subsection{Debris Flow Development in the Earthquake Triggered Hazard Areas}

After the Wenchuan earthquake, Chen et al. [44] and Cui et al. [30] intensively studied the characteristics of the debris flows in the Wenchuan area and found that during the first two years after the earthquake, the debris flow activity increased rapidly because of the heavy precipitation, abundant source material, and blocked valleys. Subsequently, activity of debris flows diminished as a result of the decrease in the amount of loosened soil. The authors predicted the active period would last fifteen years. Similarly, Chen et al. [50] studied the relationship between earthquakes and debris flows, finding that land forms, precipitation, and source material are the three key factors for debris flow initiation in the earthquake area. Based on historical observations at other earthquake areas, they predicted that the impact of the Wenchuan earthquake on local debris flows would be significant in the next five to six years and would have a lasting impact for twenty years, and that the debris flow system would eventually reach a relatively stable stage. These two conclusions effectively explain the debris flow development results in the present study. During the first year after the earthquake, the geologic hazards triggered by the earthquake, such as collapses and landslides, brought abundant loose solid masses. The surface disturbance and vegetation destruction triggered by aftershocks changed the surface water infiltration and runoff processes, and facilitated the formation of soil erosion and flooding. Meanwhile, heavy rainfall flushed the slope, carried the loose mass, and eventually formed debris flows. For example, heavy rainfalls on 24 September 2008, in Beichuan County, 13 August 2010, in Qingping Town, and 14 August 2010, in Yingxiu Town induced catastrophic debris flows. During the first year after the earthquake, debris flows occurred frequently in the earthquake-affected region 
with a development rate of $10.2 \%$. After two or three years, because the loose soil source decreased, along with decreased aftershocks, the intensity of the debris flows decreased, although the debris flow activity was still in progress. The average rate of debris flow development between 2008 and 2011 was 3\%.

Lithology plays a dominant role in the formation of debris flows in the study sites. The lithology data in the hazard region (Table 6) were interpreted from the China geological map and classified into three cases. The first case is glutenite and limestone, and included the No. 1, No. 2, No. 6, No. 10 and No. 11 sites. These metamorphic rocks represent good soil-forming conditions, and facilitate the formation of debris flow and vegetation recovery. The second case was for sites composed of granite and diorite with little soil development and large broken boulders after the earthquake. These conditions resulted in limited debris flow and vegetation recovery, and included the No. 3, No. 7, No. 9, No. 12 and No. 14 sites. Moreover, this lithology has a dominant proportion in the lithology of stable region. The third case was for sites composed of limestone splint rock, a sedimentary rock with moderate soil-forming conditions with less soil and small broken rock particles than glutenite. Sites No. 4, No. 5, No. 8, No. 13 and No. 15 were classified as limestone splint rock cases and had moderate debris flow and vegetation recovery.

Table 6. Lithology of the selected hazards sites.

\begin{tabular}{cccc}
\hline No. & Longitude & Latitude & Lithology \\
\hline 1 & 104.122 & 31.5519 & glutenite, limestone \\
2 & 104.56 & 31.9247 & glutenite, limestone \\
3 & 103.64 & 31.2122 & granite, diorite \\
4 & 103.999 & 31.4576 & limestone splint rock \\
5 & 104.146 & 31.4839 & quartzose sandstone \\
6 & 104.811 & 32.1836 & glutenite, limestone \\
7 & 103.464 & 31.0672 & granite, diorite \\
8 & 104.124 & 31.5096 & quartzose sandstone \\
9 & 103.945 & 31.5051 & granite, diorite \\
10 & 104.441 & 31.8251 & glutenite, limestone \\
11 & 104.669 & 32.052 & glutenite, limestone \\
12 & 103.509 & 31.3697 & granite, diorite \\
13 & 104.031 & 31.6379 & limestone splint rock \\
14 & 103.959 & 31.5263 & granite, diorite \\
15 & 104.115 & 31.6402 & limestone splint rock \\
\hline
\end{tabular}

The debris flow development was also analyzed according to elevation and slope data (Figure 10). The newly developed debris flows mainly occurred in elevations below 2,000 m, accounting for $92.02 \%$ and $88.23 \%$ of the total debris flow area in 2008 to 2009 and 2009 to 2011, respectively. The debris flows also occurred on slopes of 0 to $50^{\circ}$, which account for $93.86 \%$ and $90.12 \%$ of the total debris flow area in 2008 to 2009 and 2009 to 2011, respectively. Large-scale landslides produced relatively large debris flows, such as the large-scale landslides in Wenjiagou, Qingping Town (site No. 1) and Yingxiu Town, Wenchuan County (site No. 7). 
Figure 10. Relationship between newly developed debris flow area and topographic factors.
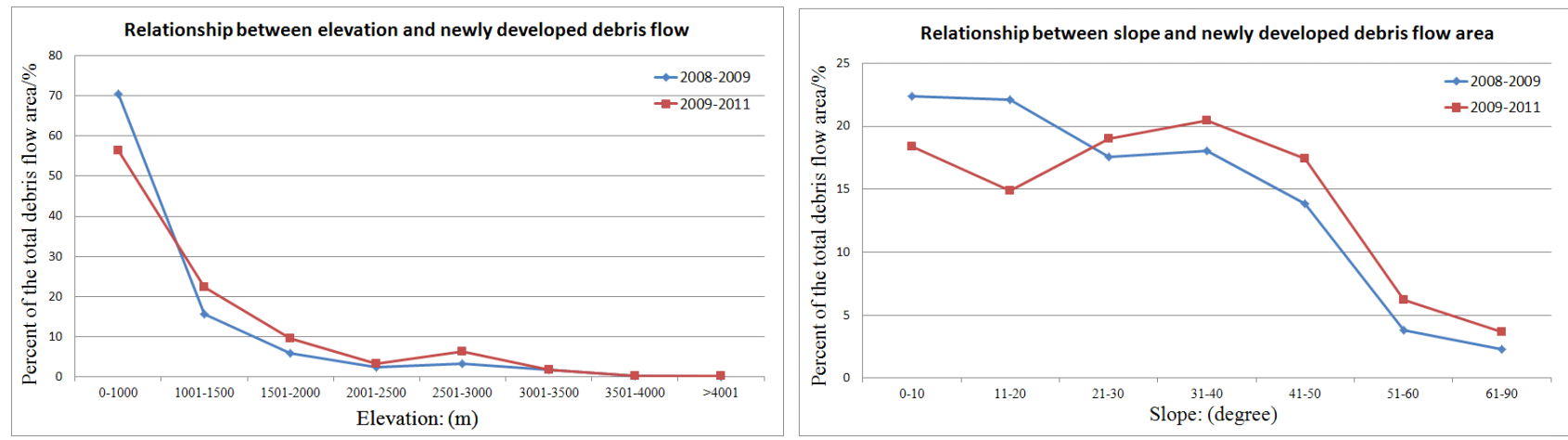

\subsection{Vegetation Recovery in the Earthquake Triggered Hazard Areas}

Opinions differ with regard to the potential for vegetation recovery in the hazard region. Zhang et al. [24] thought that an ecological restoration of the areas affected by landslides would be quite difficult because of the severe damage to the local environment caused by the earthquake. In contrast, Zhang et al. [51] researched the impact of the Wenchuan earthquake on biodiversity and found that despite bare rocks comprising the largest area of ground cover in the earthquake-damaged areas, a high percentage of the damaged areas contained remnant vegetation, suggesting that future vegetation recovery is likely. An experiment done by Bormann et al. [52] in 1981 also found that forest ecosystems had strong self-healing capabilities after the external environment had changed, as happens with earthquakes and forest fires, and the seeds buried in the soil or under the surface would play an important role in the process of vegetation recovery. During the first year after the earthquake, the seeds sprout quickly from the soil, and the dominate species are herbaceous plants. Other previous studies suggested that the presence of remnant vegetation is a driving factor for forest recovery [53,54]. Furthermore, Liu et al. [36] found that local vegetation productivity in heavily affected areas had recovered to $84 \%$ and $87 \%$ after one and two months, respectively.

Our results demonstrate the possibility of vegetation recovery in earthquake-affected areas even under harsh conditions in some areas, and a positive correlation was found with geological hazard variation (Figure 11). In the one to two years after the earthquake, the loose soil produced by the earthquake combined with the sliding of the entire landslide mass in some hazard regions made it easier for the vegetation to recover. Community types of shrub and grass grew quickly in this period, resulting in the fastest vegetation recovery period. Subsequently, the vegetation recovery slowed due to woody plant re-establishment. The recovery patterns in the hazard areas were complex, with factors such as the terrain and soil also affecting the recovery's progress [3] and making vegetation recovery difficult (as with the No. 14 and No. 15 sites in Table 5).

Similarly, the vegetation recovery was analyzed according to elevation and slope data (Figure 12). The vegetation recovery mainly occurred in elevations below $3,000 \mathrm{~m}$, accounting for $99.27 \%$ and $99.15 \%$ of the total debris flow area in 2008 to 2009 and 2009 to 2011, respectively, and the peak occurred between the elevation of 1001-1500 m because of the abundant accumulational soil mass, which was suitable for vegetation growth, produced by the landslides and debris flows. The slope of the surface also have a obvious influence on the progress of vegetation recovery, and more than $60 \%$ of the vegetation recovery were concentrated on slopes between $31^{\circ}$ and $50^{\circ}$, the peak occurred 
between the slope of $41-50^{\circ}$, Lin et al. [55] and Lu et al. [3] also observed similar results, they suggested that grass species that survived during this slope range facilitated the vegetation growth when adequate rainfall was supplied to the area. In addition, the good soil holding and storing water condition for the plants in the hazard sites is also critical to the vegetation recovery.

Figure 11. Relationship between vegetation recovery and geological hazards development from 2008 to 2011.

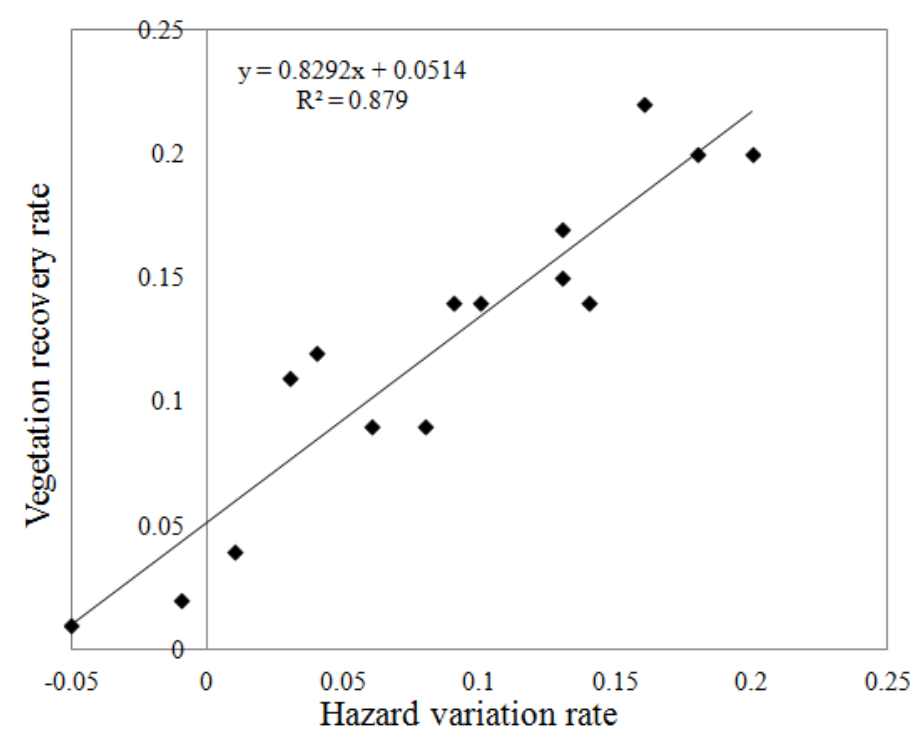

Figure 12. Relationship between vegetation recovery and topographic factors.
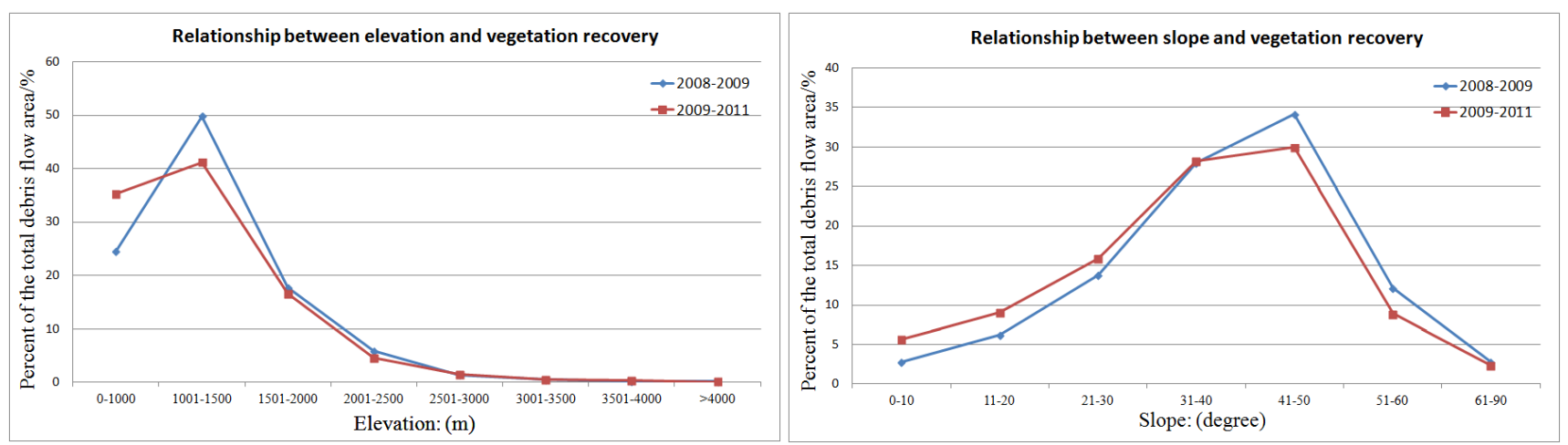

\section{Conclusions}

Remote sensing technology can improve the efficiency of disaster monitoring. This study used airborne optical images to monitor the development of secondary hazards and vegetation recovery in post-earthquake areas, and the results were validated through field investigation.

During the first year after the earthquake, debris flow activity occurred frequently with high intensity. After the source material became less available and the slope structure stabilized, the intensity of the debris flows trended down. The average annual rate of newly developed debris flows between 2008 and 2011 was approximately 3\%. After the first year, the debris flow and vegetation recovery activity gradually diminished, and the hazard area gradually decreased to $12 \%$. The lithology and topography had an influence on the debris flow development process. 
Observations in the post-earthquake hazard areas from 2008 to 2011 showed vegetation recovery in these areas was possible, and the greatest vegetation recovery occurred two or three years after the earthquake. However, the vegetation recovery rate was related to debris flow development, and was in agreement with post-earthquake geologic hazard development. The fastest vegetation recovery period was the first one to two years after the earthquake. Afterwards, the vegetation recovery gradually slowed. The average recovery rate between 2008 and 2011 was 15\% to 20\%. Thus, the results of this paper predict that at least five to ten years are needed to achieve total vegetation recovery. In addition, the elevation below $1500 \mathrm{~m}$ and slope between $31^{\circ}$ and $50^{\circ}$ has the fastest rate of vegetation growth.

Given the various performances of the different hazard sites, future studies should consider the whole disaster area as the research area. Other factors such as the soil structure [56,57], terrain [58,59], and regional climate $[60,61]$ provide more accurate data for decision making. To acquire a better understanding of the hazard development and vegetation restoration processes, longer-term observations, such as ten to twenty years, must be conducted [62].

\section{Acknowledgments}

The authors gratefully acknowledge financial support provided for this research from the Interdisciplinary and Collaborative S\&T Innovation Research Team on Advance Earth Observation System CAS and the External Cooperation Program of the Chinese Academy of Sciences (GJH21123). We also thank all the anonymous reviewers for their valuable comments, which substantially improved our paper.

\section{Author Contributions}

Zhenwang Li and Quanjun Jiao performed the analyses and prepared the paper. Liangyun Liu provided the technical guidance and contributed to the discussion. Zhenwang Li, Huan Tang, and Quanjun Jiao helped the collection of field data. Tong Liu helped provide airborne remote sensing images.

\section{Conflicts of Interest}

The authors declare no conflict of interest.

\section{References}

1. Cui, P.; Zhu, Y.-Y.; Han, Y.-S.; Chen, X.-Q.; Zhuang, J.-Q. The 12 May Wenchuan earthquake-induced landslide lakes: Distribution and preliminary risk evaluation. Landslides 2009, 6, 209-223.

2. Han, J.; Wu, S.; He, S.; Sun, W.; Zhang, C.; Wang, T.; Yang, J.; Si, J. Basal characteristics and formation mechanisms of geological hazards triggered by the May 12, 2008 Wenchuan earthquake with a moment magnitude of 8.0. Earth Sci. Fontiers 2009, 16, 306-326. (In Chinese)

3. Lu, T.; Zeng, H.; Luo, Y.; Wang, Q.; Shi, F.; Sun, G.; Wu, Y.; Wu, N. Monitoring vegetation recovery after China's May 2008 Wenchuan earthquake using landsat tm time-series data: A case study in Mao County. Ecol. Res. 2012, 27, 955-966. 
4. Cui, P.; Wei, F.; Chen, X.; He, S. Geo-hazards in Wenchuan earthquake area and countermeasures for disaster reduction. Bull. Chin. Acad. Sci. 2008, 23, 317-323.

5. $\mathrm{Li}, \mathrm{Z}$. The state of the art of the research on seismic landslide hazard at home and abroad. J. Catastrophol. 2003, 18, 64-70.

6. Tronin, A. Satellite remote sensing in seismology. A review. Remote Sens. 2009, 2, 124-150.

7. Dong, Y.; Li, Q.; Dou, A.; Wang, X. Extracting damages caused by the 2008 Ms 8.0 Wenchuan earthquake from SAR remote sensing data. J. Asian Earth Sci. 2011, 40, 907-914.

8. Ehrlich, D.; Guo, H.D.; Molch, K.; Ma, J.W.; Pesaresi, M. Identifying damage caused by the 2008 Wenchuan earthquake from VHR remote sensing data. Int. J. Digit. Earth 2009, 2, 309-326.

9. Ellen, R.; Robert, K.; Kyu-Seok, W. Remote sensing observations of landslides and ground deformation from the 2004 Niigata Ken Chuetsu earthquake. Jpn. Geotech. Soc. 2006, 46, 831-842.

10. Fu, B.; Ninomiya, Y.; Lei, X.; Toda, S.; Awata, Y. Mapping active fault associated with the 2003 Mw 6.6 Bam (Se Iran) earthquake with ASTER 3D images. Remote Sens. Environ. 2004, 92, $153-157$.

11. Guo, H.; Liu, L.; Fan, X.; Li, X. Study of earth observation for disaster reduction in Wenchuan and Yushu earthquakes. Geol. J. China Univ. 2011, 17, 1-12. (In Chinese)

12. Yusuf, Y.; Matsuoka, M.; Yamazaki, F. Damage assessment after 2001 Gujarat earthquake using Landsat-7 satellite images. J. Indian Soc. Remote Sens. 2001, 29, 17-22.

13. Safari, H.O.; Pirasteh, S.; Pradhan, B.; Gharibvand, L.K. Use of remote sensing data and GIS tools for seismic hazard assessment for shallow oilfields and its impact on the settlements at Masjed-i-Soleiman area, Zagros mountains, Iran. Remote Sens. 2010, 2, 1364-1377.

14. Liou, Y.A.; Sha, H.C.; Chen, T.M.; Wang, T.S.; Li, Y.T.; Lai, Y.C.; Chiang, M.H.; Lu, L.T. Assessment of disaster losses in rice paddy field and yield after Tsunami induced by the 2011 great east Japan earthquake. J. Mar. Sci. Technol.-Taiwan 2012, 20, 618-623.

15. Kulawardhana, R.W. Remote sensing and GIS technologies for monitoring and prediction of disasters. Int. J. Digit. Earth 2011, 5, 88-90.

16. Gorum, T.; Fan, X.; van Westen, C.J.; Huang, R.Q.; Xu, Q.; Tang, C.; Wang, G. Distribution pattern of earthquake-induced landslides triggered by the 12 May 2008 Wenchuan earthquake. Geomorphology 2011, 133, 152-167.

17. Zhang, B.; Jiao, Q.; Wu, Y.; Zhang, W. Estimating soil erosion changes in the Wenchuan earthquake disaster area using geo-spatial information technology. J. Appl. Remote Sens. 2009, 3, doi:10.1117/1.3153914.

18. Klose, C.D. Evidence for anthropogenic surface loading as trigger mechanism of the 2008 Wenchuan earthquake. Environ. Earth Sci. 2011, 66, 1439-1447.

19. Li, Z.; Chen, Q.; Zhou, J.; Tian, B. Analysis of synthetic aperture radar image characteristics for seismic disasters in the Wenchuan earthquake. J. Appl. Remote Sens. 2009, 3, doi: $10.1117 / 1.3153906$.

20. Tong, X.; Sandwell, D.T.; Fialko, Y. Coseismic slip model of the 2008 Wenchuan earthquake derived from joint inversion of interferometric synthetic aperture radar, GPS, and field data. J. Geophys. Res.: Solid Earth 2010, 115, doi:10.1029/2009JB006625. 
21. Lei, L.; Liu, L.; Zhang, L.; Bi, J.; Wu, Y.; Jiao, Q.; Zhang, W. Assessment and analysis of collapsing houses by aerial images in the Wenchuan earthquake. J. Remote Sens 2010, 14, 333-344.

22. Liu, L.; Wu, Y.; Zuo, Z.; Chen, Z.; Wang, X.; Zhang, W. Monitoring and assessment of barrier lakes formed after the Wenchuan earthquake based on multitemporal remote sensing data. J. Appl. Remote Sens. 2009, 3, doi:10.1117/1.3153915.

23. Sato, H.; Harp, E. Interpretation of earthquake-induced landslides triggered by the 12 May 2008, M7.9 Wenchuan earthquake in the beichuan area, sichuan province, China using satellite imagery and google earth. Landslides 2009, 6, 153-159.

24. Zhang, W.; Lin, J.; Peng, J.; Lu, Q. Estimating Wenchuan earthquake induced landslides based on remote sensing. Int. J. Remote Sens. 2010, 31, 3495-3508.

25. Wang, X.; Dou, A.; Ding, X. Study on Quantitative Earthquake Damage of Dujiangyan City, Caused by $2008 \mathrm{MS}=8.0$ Wenchuan, China Earthquake Based on Aerial Imagery. In Proceedings of the 2010 IEEE International Geoscience and Remote Sensing Symposium (IGARSS), Honolulu, HI, USA, 25-30 July 2010; pp. 2743-2746.

26. Brown, D.; Saito, K.; Liu, M.; Spence, R.; So, E.; Ramage, M. The use of remotely sensed data and ground survey tools to assess damage and monitor early recovery following the 12.5.2008 Wenchuan earthquake in China. Bull. Earthq. Eng. 2011, 10, 741-764.

27. Cao, C.; Chang, C.; Xu, M.; Zhao, J.; Gao, M.; Zhang, H.; Guo, J.; Guo, J.; Dong, L.; He, Q.; et al. Epidemic risk analysis after the Wenchuan earthquake using remote sensing. Int. J. Remote Sens. 2010, 31, 3631-3642.

28. Liou, Y.-A.; Kar, S.K.; Chang, L. Use of high-resolution formosat-2 satellite images for post-earthquake disaster assessment: A study following the 12 May 2008 Wenchuan earthquake. Int. J. Remote Sens. 2010, 31, 3355-3368.

29. Dong, J.-J.; Liou, Y.-A.; Chang, L.-Y.; Lee, C.-T.; Liao, J.-J.; Pa, Y.-W. Application of satellite images and DEM for the hazard assessment of landslide dams. J. Photogramm. Remote Sens. 2010, 15, 3-15.

30. Cui, P.; Zhuang, J.; Chen, X.; Zhang, J.; Zhou, X. Characteristics and countermeasures of debris flow in Wenchuan area after the earthquake. J. Sichuan Univ. (Eng. Sci. Ed.) 2010, 42, 10-19. (In Chinese)

31. Li, Y.; Huang, R.; Densmore, A.L.; Zhou, C.; Cao, S. Basic features and research progresses of Wenchuan MS 8.0 earthquake. J. Sichuan Univ. (Eng. Sci. Ed.) 2009, 41, 7-25. (In Chinese)

32. Yang, C.; Ren, X.; Huang, H. The vegetation damage assessment of the Wenchuan earthquake of May 2008 using remote sensing and GIS. Nat. Hazards 2011, 62, 45-55.

33. Chigira, M.; Wu, X.; Inokuchi, T.; Wang, G. Landslides induced by the 2008 Wenchuan earthquake, Sichuan, China. Geomorphology 2010, 118, 225-238.

34. Huang, R.; Li, W. Analysis of the geo-hazards triggered by the 12 May 2008 Wenchuan earthquake, China. Bull. Eng. Geol. Environ. 2009, 68, 363-371.

35. Ge, Y.; Xu, J.; Liu, Q.; Yao, Y.; Wang, R. Image interpretation and statistical analysis of vegetation damage caused by the Wenchuan earthquake and related secondary disasters. J. Appl. Remote Sens. 2009, 3, doi:10.1117/1.3141726. 
36. Liu, Y.; Liu, R.; Ge, Q. Evaluating the vegetation destruction and recovery of Wenchuan earthquake using MODIS data. Nat. Hazards 2010, 54, 851-862.

37. $\mathrm{Xu}, \mathrm{J} . ; \mathrm{Lu}, \mathrm{Y}$. Meta-synthesis pattern of post-disaster recovery and reconstruction: Based on actual investigation on 2008 Wenchuan earthquake. Nat. Hazards 2011, 60, 199-222.

38. Guo, H.; Liu, L.; Lei, L.; Wu, Y.; Li, L.; Zhang, B.; Zuo, Z.; Li, Z. Dynamic analysis of the Wenchuan earthquake disaster and reconstruction with 3 -year remote sensing data. Int. J. Digit. Earth 2010, 3, 355-364.

39. Cruden, D.M. A simple definition of a landslide. Bull. Int. Assoc. Eng. Geol. 1991, 43, $27-29$.

40. Turner, A.K.; Schuster, R.L. Landslides: Investigation and Mitigation; Transportation Research Board, Special Report 247; National Academy Press: Washington, DC, USA, 1996; p 129-177.

41. Highland, L.M.; Bobrowsky, P. The Landslide Handbook: A Guide to Understanding Landslides; U.S. Geological Survey Circular 1325: Reston, VA, USA, 2008; p 129.

42. Highland, L.; Ellen, S.D.; Christian, S.B.; Brown, W.M., III. Debris-Flow Hazards in the United States; U.S. Department of the Interior, U.S. Geological Survey: Denver, CO, USA, 1997.

43. Ren, Z.; Lin, A. Co-seismic landslides induced by the 2008 Wenchuan magnitude 8.0 earthquake, as revealed by ALOS PRISM and AVNIR2 imagery data. Int. J. Remote Sens. 2010, 31, 3479-3493.

44. Chen, X.; Cui, P.; Li, Y.; Gao, Q.; Zhao, W. Mountain hazard induced by Wenchuan earthquake and its long-term development trends of Ganxi Gully, Beichuan. J. Sichuan Univ. (Eng. Sci. Ed.) 2010, 42, 22-32. (In Chinese)

45. Qi, X.; Tang, C.; Chen, Z.; Shao, C. Coupling analysis of control factors between earthquake-induced landslides and subsequent rainfall-induced landslides in epicenter area of Wenchuan earthquake. J. Eng. Geol. 2012, 20, 522-531.

46. Yi, G.; Long, F.; Zhang, Z. Spatial and temporal variation of focal mechanisms for aftershocks of the $2008 \mathrm{M}_{\mathrm{s}} 8.0$ Wenchuan earthquake. Chin. J. Geophys. 2012, 55, 1213-1227. (In Chinese)

47. Li, Y.; Chen, L.; Lu, Y.; Zhan, Z. Numerical simulation on influences of Wenchuan earthquake on the stability of faults in the neighborhood. Earth Sci. (J. China Univ. Geosci.) 2013, 38, 398-410. (In Chinese)

48. Hua, W.; Chen, Z.; Li, Z.; Zhao, C.; Wang, Q.-C. Seismic triggering and the aftershock distribution of the Wenchuan M8.0 earthquake. Earthquake 2009, 29, 33-39.

49. Masoud, A.; Koike, K. Relationship between remotely sensed vegetation change and fracture zones induced by the 2008 Wenchuan earthquake, China. J. Earth Sci. 2013, 24, 282-296.

50. Chen, N.-S.; Hu, G.-S.; Deng, M.-F.; Zhou, W.; Yang, C.-L.; Han, D.; Deng, J.-H. Impact of earthquake on debris flows - A case study on the Wenchuan earthquake. J. Earthq. Tsunami 2011, 5, 493-508.

51. Zhang, J.; Hull, V.; Xu, W.; Liu, J.; Ouyang, Z.; Huang, J.; Wang, X.; Li, R. Impact of the 2008 Wenchuan earthquake on biodiversity and giant panda habitat in Wolong Nature Reserve, China. Ecol. Res. 2011, 26, 523-531.

52. Bormann, F.H.; Likens, G.E. Pattern and Process in a Forested Ecosystem: Disturbance, Development, and the Steady State Based on the Hubbard Brook Ecosystem Study; Springer-Verlag: New York, USA, 1994; p 207.

53. Ferguson, B.G.; Vandermeer, J.; Morales, H.; Griffith, D.M. Post-agricultural succession in el petén, guatemala. Conserv. Biol. 2003, 17, 818-828. 
54. Holl, K.D.; Loik, M.E.; Lin, E.H.V.; Samuels, I.A. Tropical montane forest restoration in Costa Rica: Overcoming barriers to dispersal and establishment. Restor. Ecol. 2000, 8, 339-349.

55. Lin, W.-T.; Chou, W.-C.; Lin, C.-Y.; Huang, P.-H.; Tsai, J.-S. Vegetation recovery monitoring and assessment at landslides caused by earthquake in central Taiwan. For. Ecol. Manag. 2005, 210, 55-66.

56. Mhaske, S.Y.; Choudhury, D. GIS-based soil liquefaction susceptibility map of Mumbai city for earthquake events. J. Appl. Geophys. 2010, 70, 216-225.

57. Brocca, L.; Ponziani, F.; Moramarco, T.; Melone, F.; Berni, N.; Wagner, W. Improving landslide forecasting using ASCAT-derived soil moisture data: A case study of the Torgiovannetto landslide in central Italy. Remote Sens. 2012, 4, 1232-1244.

58. Kamp, U.; Growley, B.J.; Khattak, G.A.; Owen, L.A. GIS-based landslide susceptibility mapping for the 2005 Kashmir earthquake region. Geomorphology 2008, 101, 631-642.

59. Lee, S.; Talib, J. Probabilistic landslide susceptibility and factor effect analysis. Environ. Geol. 2005, 47, 982-990.

60. Wang, L.; Shum, C.K.; Simons, F.J.; Tassara, A.; Erkan, K.; Jekeli, C.; Braun, A.; Kuo, C.; Lee, H.; Yuan, D.-N. Coseismic slip of the $2010 \mathrm{Mw} 8.8$ Great Maule, Chile, earthquake quantified by the inversion of GRACE observations. Earth Planet. Sci. Lett. 2012, 335-336, 167-179.

61. Li, A.; Wang, A.; Liang, S.; Zhou, W. Eco-environmental vulnerability evaluation in mountainous region using remote sensing and GIS-A case study in the upper reaches of Minjiang river, China. Ecol. Model. 2006, 192, 175-187.

62. Lu, T.; Shi, F.; Sun, G.; Luo, Y.; Wang, Q.; Wu, Y.; Wu, N. Reconstruction of the Wenchuan earthquake-damaged ecosystems: Four important questions. Chin. J. Appl. Environ. Biol. 2010, $16,301-304$.

(C) 2014 by the authors; licensee MDPI, Basel, Switzerland. This article is an open access article distributed under the terms and conditions of the Creative Commons Attribution license (http://creativecommons.org/licenses/by/3.0/). 